\title{
ENTRE A DOCUMENTAÇÃO E A PRODUÇÃO ARTÍSTICA: \\ Peter Funch e as encruzilhadas da fotografia contemporânea
}

\author{
João Guilherme Peixoto
}

\begin{abstract}
Nascida em meio a uma das mais importantes revoluções da humanidade - a Revolução Industrial - a fotografia, desde seu surgimento, abraçou para si os ideais transformadores desta: desenvolvimento, ruptura com o passado, necessidade de expansão. $\mathrm{O}$ entrelaçamento (ou seria a convergência?) entre uma realidade mecânica (óptica) e a outra química (sensibilidade) possibilitou a fotografia expandir a configuração visual do homem, levando-o a romper contratos dentro da cadeia espaço-temporal de representação da realidade (como é o caso no uso da fotografia da ideia de profundidade de campo).

A modernidade da fotografia e a legitimidade de suas funções documentais apóiam-se nas ligações estritas que ela mantém com os mais emblemáticos fenômenos da sociedade industrial: o crescimento das metrópoles e o desenvolvimento da economia monetária; a industrialização; as grandes mudanças nos conceitos de espaço e de tempo e a revolução das comunicações (ROUILLÉ, 2009, p. 29).
\end{abstract}

Observa-se, pois, o surgimento de novos protocolos, novas gramáticas visuais as quais afetam tanto a cadeia produtiva quanto a lógica de recepção/consumo de imagens na sociedade. A produção de imagens sai de um setor primário (produção artesanal, unitária; participação direta do agente) para atingir uma secundidade (mecanização, utilização, serialização). A fotografia oferece à capacidade de reprodução e disseminação de conteúdo, tudo isso atrelado à participação cada vez menos relevante da figura humana. Conclui-se que a passagem da ferramenta, do pigmento para a máquina e da oficina para o laboratório, envolve a fotografia não mais no eixo da pintura, mas em um campo de produção segundo. A própria Revolução Industrial aciona na sociedade campos metafóricos de representação do real: o gás substitui o sol; o vapor, o braço humano. A fotografia integra a visão à sensibilidade química. 
[...] foi renovando o regime da verdade, nutrindo a crença de que suas imagens são 'a exatidão, a verdade, a própria realidade', que a fotografia pôde suplantar o desenho e a gravura em suas funções documentais. Essa capacidade da fotografia para reformar, na metade do século XIX, o regime de verdade, isto é, para inspirar confiança no valor documental das imagens, não se apóia somente em seu dispositivo técnico (a máquina, a impressão), mas em sua coerência com o percurso geral da sociedade. (ROUILLÉ, 2009, p. 37).

Durante todo o século XIX e ainda no início do século XX, essa reconfiguração dos modos de produzir, manipular e circular informação visual apresentou-se (e ainda apresenta-se) como uma das problemáticas mais complexas tanto no campo da fotografia como no campo da arte (COUCHOT, 2003; CRARY, 1991). Porém, com o advento da tecnologia digital e o desenvolvimento desta no campo da fotografia, outros desafios e questionamentos mostraram-se evidentes.

Como por exemplo, este: fotografia documental e fotografia "artística" são produtos de uma mesmo equação? Existe uma hierarquização quando comparados os dois gêneros? E o que (e quem) define as barreiras conceituais (e também metodológicas) de cada um desses eixos? Observa-se que, mesmo com o desenvolvimento dos suportes para captação, edição e circulação de imagens na contemporaneidade, questões referentes ao próprio surgimento da prática fotográfica ainda se fazem presentes. Mas, o que referenda essas produções?

Das formas de expressão visual da realidade social, a fotografia é aquela que ainda procura o seu lugar na sociabilidade contemporânea. Talvez porque tenha sido, por muito tempo, a mais popular de todas, ao alcance de um leque amplo de usuários e instrumentalizada por uma variedade significativa de imaginários. A que se deve agregar, em consequência, a diversidade de suas funções: das puramente técnicas às puramente artísticas, passando pelas relativas ao lazer e à memória do homem comum (LEDO, 1998, p. 72).

\section{Fotografia documental: representação de uma "realidade mais que real"?}

Atrelada a uma revolução na cadeia produtiva, a fotografia inaugura na sociedade uma visibilidade atrelada a novas gramáticas visuais. Buscando captar o real em sua essência, os modos de ver atribuídos a fotografia em seus primórdios (século XIX) constituíram-se das mudanças ocorridas nas sociedades modernas. A urbanização e o expansionismo de meados do século XIX capitaneiam essas alterações. Todavia, esta "nova 
maneira de ver" representa uma afronta ao campo da arte. Diferentemente da pintura, por exemplo, a fotografia representaria todo o visível, visto ou não visto, sem seleção e sem perda (ROUILLE, 2009).

Tal urbanidade inaugura para a fotografia a ideia de representação, de reportação da realidade. Figuras como Weegee, Brassai e Krull aproveitam-se de movimentos tipicamente decorrentes da Revolução Industrial (aumento da violência e dos problemas atrelados a ela) para produzir imagens, as quais buscavam retratar entre outras realidades, aquelas muito mais sujas e indiscretas.

Já quando observamos as repercussões do fenômeno experimental no campo da fotografia, podemos designar sua captação com a própria essência da Revolução Industrial: reprodutibilidade, mobilidade, rapidez de produção. Estas características permitem a fotografia transitar na sociedade como mediadora entre o mundo e os próprios homens. Entretanto, apenas no século XX, a atividade fotográfica atingiria uma escala mais expressiva, momento crucial para o desenvolvimento do fotojornalismo.

Técnica e economia sobrepõem-se a estética. A transferência para o campo da técnica e da economia, em detrimento da estética, autoriza a fotografia a transitar no território do lucro, da potencialidade econômico-financeira. Todos esses fenômenos descritos acima situam a fotografia no campo de uma suposta "auto-reputação", uma atribuição deveras complexa, a qual foge ao regime da transcendência (plano do real para o plano das subjetividades) e, supostamente, introduz essa prática no campo da imanência (significação por si só). De acordo com Rouille, "o plano da imanência traçado pela fotografia, no qual o real substitui o ideal transcendente, é o território do verdadeiro fotográfico”.

Ainda no início do século XX, parâmetros artístico-estéticos não compunham o rol de "funcionalidades" da fotografia. Esta estaria consagrada como documento; reflexo cabal da sociedade. Ao contrário das representatividades estéticas e artísticas da fotografia, a chamada fotografia documental buscaria intencionalmente o palpável, o pré-existente, o material. Essa proposta, possibilitada pela convergência entre um universo mecânico e outro químico leva a uma ética da exatidão e a uma estética da transparência.

Para justificar essa atribuição referenciada na prática fotográfica cotidiana, alguns pesquisadores e produtores do campo fotográfico argumentaram a favor de uma suposta essência de realidade implícita ao documento fotográfico, uma espécie de sistema de crença no suporte que o gênero documental mostrava-se capaz de validar no público. Mas, o que sustentava essa crença na exatidão, verdade e realidade da fotografia-documento? Podemos elencar alguns aspectos, a saber:

1. A fotografia aperfeiçoa, racionaliza e mecaniza a razão visual. Exemplos: ideia da perspectiva e emprego da câmera escura. Começa aqui o processo de virtualização do real, no sentido expansivo. Usam-se conceitos do campo das ciências para ampliar nosso campo de visualidade, para mediar o campo das percepções. 
2. A fotografia associa essa mecanização da mimese ocular com outro acionador de exatidão: o registro químico das aparências. Eis o implemento de uma acessível verdade tátil (a impressão).

3. Mudanças profundas na própria economia da imagem. O paradigma artesanal em conflito com o paradigma industrial. Rompimento da unidade artista/obra.

4. O "documental" deixa de apoiar-se estritamente no artista, na subjetividade deste. Positivismo/Iluminismo/Racionalismo influem diretamente nessa reconfiguração.

5. Aspectos relacionados à nitidez, ao enquadramento e à seleção de equipamento também se articulam com a produção documental fotográfica e suas repercussões sociais.

Contudo, atualmente, decorrente do advento das sociedades da informação e da proliferação das mídias, o documento fotográfico (como tal) entra em crise, visto que algumas constatações acerca da própria produção do documento fotográfico começam a ser questionadas:

a) O documento constituiu-se apenas dos elementos visíveis que compõem as imagens captadas?

b) A subjetividade desconfigura o documento fotográfico?

c) A sociedade da informação requer novos regimes de verdade e de representação. A fotografia compõe-se de elementos, muitas vezes, externos ao tradicional campo da fotografia: são projeções de softwares de modelagem 3D, avatares, clones, entre outros recursos utilizados.

\section{Fotografia de arte: uma saída interessante para compreender a fotografia hoje?}

O conflito gerado entre documentação e arte na prática fotográfica remete ao próprio surgimento da atividade. Se no regime de documentação podemos encontrar como elemento de valoração, o regime de representação de uma realidade palpável e tangível, a fotografia no campo das artes busca sublimar tal arranjo. O desejo aqui é orientar a prática para valores associados à subjetividade, à estética, à poética, entre outros.

Compreender a produção fotográfica como expressão artística é atestar que toda fotografia não nos apresenta a realidade. Somos transportados e nessa "realidade paralela" buscamos o que nos apetece. A fotografia nos serve para coletar o agradável, para dar 
vazão a uma fruição sem fronteiras negativas, sem traumas nem sofrimentos. A construção do real é filtrada por nossos traumas, nossas necessidades de assepsia social e cultural. Evidenciamos o que nos apetece. Resultado: a construção de uma espécie de mitologia pessoal.

Toda fotografía es una ficción que se presenta como verdadera. Contra lo que nos han inculcado, contra lo que solemos pensar, la fotografía miente siempre, miente por instinto, miente porque su naturaleza no le permite hacer otra cosa. Pero lo importante no es esa mentira inevitable. Lo importante es cómo la usa el fotógrafo, a qué intenciones sirve. Lo importante, en suma, es el control ejercido por el fotógrafo para imponer una dirección ética a su mentira. El buen fotógrafo es el que miente bien la verdad (FONTCUBERTA, 1997, p.15).

Mas, se para o regime de documentação, valores como similitude ao real, objetividade e padronização processual representariam questões que mensurariam, em teoria, essa capacidade de apresentação de uma realidade "mais que real" para a produção fotográfica, que valores poderiam ser elencados no campo da $\operatorname{arte}^{13}$ ?

Vislumbra-se a questão da autoria como um dos principais elementos que balizam a questão da valoração na fotografia "de arte". Tal definição articula-se diretamente à ideia de marca, a capacidade de desenvolvimento de um produto original com registro próprio, com personalidade e originalidade. Para o campo do cinema, por exemplo, a chamada "teoria do autor" apresentou-se como a afirmação de tais preceitos. Todavia, tal debate acerca da originalidade, frequentemente, é norteado por conceitos e hipóteses dos teóricos românticos (BUSCOMBE, 2005), os quais a compreendem como algo reservado aos grandes artistas, os grandes gênios da raça:

Por um processo de comparação com outros filmes, é possível decifrar não uma mensagem ou multividencia coerentes, mas uma estrutura que está subjacente ao filme e o modela, lhe dá um certo padrão de energia catéctica. É essa estrutura que a análise proposta pela teoria do autor liberta do filme. A estrutura está associada a um único realizador, um indivíduo, não porque desempenhe o papel de artista, exprimindo-se a si ou à sua visão no filme, mas porque é através da força das suas preocupações que uma sig-

|||||||||||||||||||||||||||||||||||||||||||||||||||||||||||

13 Vale ressaltar que o debate aqui proposto acerca das questões sobre valor não representam, simplesmente, uma celeuma polarizada entre o "gosto" e as "preferências", aspectos que se aproximam de um imperativo de valor, uma busca estrita pelo "melhor", pelo "agradável” (CONNOR, 1994). Abordamos a discussão de valor tentando nos afastar da visão estrita do entrelaçamento com as questões de particularização, de afirmação única da subjetividade, buscando em precedentes sócio-históricos orientações para nossos argumentos. Acreditamos que tal postura concebe elementos importantes para a compreensão não somente da produção fotográfica, mas também de outras áreas afins. 
nificação não intencional e inconsistente pode ser decodificada no filme, habitualmente para grande surpresa do indivíduo em questão (WOLLEN In BUSCOMBE, 2005, p. 20).

Contudo, diferentemente da visão oitocentista romântica da originalidade atrelada à genialidade, podemos identificar, no campo da fotografia, uma articulação entre participantes para concepção da imagem fotográfica. Tal divisão do trabalho não está orientada simplesmente para a cadeia de produção, mas também para as relações de edição e circulação de conteúdo. Podemos compreender a fotografia contemporânea como uma prática na qual vários sujeitos agregam saberes para produção desse conteúdo, o qual se mostra cada vez mais articulado e disperso em meio a rede mundial de computadores.

Todavia, não podemos mencionar que tal atributo (cadeias de produção, edição e circulação fotográfica coletivizada) seja exclusivo à metodologia contemporânea no campo da fotografia. Desde seu surgimento, o procedimento para obtenção das imagens perpassa a individualização e recai sobre a divisão, sobre a pulverização das atividades que compõem o ciclo da atividade.

Some art photographers, like Edward Weston, always made their own prints, regarding printing as integral to the making of the picture; others, like Henri Cartier-Bresson, never made their own prints, leaving that to technicians who knew how they wanted it done $^{14}$ (BECKER, 2008, p. 65).

\section{Entre o documental e o conceitual: Peter Funch e as encruzi- Ihadas da fotografia contemporânea}

Realmente, há como definir barreiras e limites precisos entre os campos da documentação e da arte na produção fotográfica contemporânea? A imagem fotográfica como obra de arte mostra-se efetivamente para a busca de uma referência própria para essa "função" da fotografia no mundo atual. Mas, isso significa afastá-la do campo documental? Ao contrário. A contemporaneidade, cada vez mais, articula esses dois polos, essas duas vertentes.

O status indefinido da fotografia artística contemporânea, como dispositivo para documentar uma performance ou um acontecimento, e também como obra de arte legível em si mesma. A fotografia é a um tempo um modo prático de fixar a observação,

|||||||||||||||||||||||||||||||||||||||||||||||||||||||||

14 [Tradução Livre] Alguns fotógrafos de arte, como Edward Weston, sempre fizeram suas próprias impressões, a respeito de impressão como parte integrante da tomada da foto, outros, como Henri Cartier-Bresson, nunca fizeram as suas próprias impressões, deixando isso para os técnicos que sabiam como eles queriam que fosse feito. 
e também o meio pelo qual entra em vigor esse jogo de registros visuais (COTTON, 2010, p. 39).

A produção de alguns artistas contemporâneos exemplifica essa abordagem convergente entre os campos da documentação e da produção artística no universo fotográfico. Um exemplo de possibilidade de interconexão entre estas searas é a produção do dinamarquês Peter Funch. Fotógrafo, começou sua carreia no fotojornalismo, ainda com 27 anos, na cidade de Hadsten, na Dinamarca. Contudo, decidiu investir em uma produção mais autoral e com elementos conceituais os quais ultrapassavam as propostas da fotografia de imprensa, que tem como um dos pilares o recorde visual da realidade que nos cerca.

Em Babel Tales, série em que o dinamarquês explora o cotidiano das esquinas da cidade de Nova Iorque utilizando-se de elementos que remetem a linguagem documental (mínima interferência na cena representada, por exemplo), o que se vê, na verdade, é um trabalho que envolve uma extensão da relação tempo-espaço na fotografia associado a um intenso trabalho de manipulação digital das imagens. Aquelas situações retratadas não foram captadas, são fruto de uma seleção de mais de dez mil imagens, as quais foram sobrepostas em um software de edição. Segundo o fotógrafo, a ideia de produzir a série decorreu da análise das imagens das câmeras de segurança da cidade de Nova York. Funch observou que a ideia de interação social para aquele grupo em destaque nada mais representava que uma ficção, visto que não há qualquer tipo de comunicação entre os envolvidos. Suas imagens, pois, buscam este estado de coletividade, de comunhão entre os representados. Pode-se dizer que Babel Tales é uma crítica à sociedade contemporânea, ao processo de globalização e a própria ideia de desenvolvimento.

Em todos os sentidos possíveis da palavra, a arte abusa. Acentua, aumenta, intensifica. Como a caricatura e a comédia, ela exagera, ressalta os traços. Como a tragédia, ela chega a desmesura, a exorbitância, ao extremo, ao abismo. Busca o estado paroxístico, exacerba-o, vai além dele. E ainda: abusa de seu poder, abusa da situação, abusa dos acontecimentos cruéis sobre os quais ela produz imagens sublimes (GALARD, 2012, p. 59).

Já em seu trabalho Aftermath 9/11, uma série produzida no Ground Zero, em Nova Iorque, em 2001, após o atentado conhecido internacionalmente como "Onze de Setembro", pode-se destacar a produção de retratos os quais extrapolam os limites conceituais apresentados por outros campos da fotografia, como, por exemplo, a fotografia de imprensa. Diferentemente de uma cobertura pautada nas clássicas relações de noticiabilidade e interesse público (típicas do universo jornalístico), Funch desenvolve uma série de retratos os quais buscam articular elementos da fotografia documental e conceitual para representar a angústia vivida por cidadãos comuns em um momento de 
perda e sofrimento. As máscaras nos rostos dos personagens e o controle do processo de produção (as imagens foram produzidas em estúdio) nos permitem ir além do debate sobre velocidade e instantaneidade da informação na cadeia de circulação da fotografia na contemporaneidade e nos apresentam outras chaves de leitura.

\begin{abstract}
Não se pode esquecer que à imagem fotográfica é conferido um papel moral, que transforma o retrato no exemplo visível de virtudes e comportamentos a serem partilhados pela sociedade. Se assim não fosse, como explicar a moda dos retratos de celebridades, que deveriam fornecer os necessários exemplos morais a seus contemporâneos? (FABRIS, 2004, p. 39).
\end{abstract}

\title{
Conclusão
}

Diante do exposto, podemos identificar atributos que, em teoria, definem os gêneros documental e artístico para o campo da fotografia. Porém, é importante salientar que, contemporaneamente, os limites que separam essas duas práticas estão se tornando cada vez menos identificáveis, visto que, com o advento e o desenvolvimento das tecnologias digitais somados a mudanças nas cadeias de produção, edição e circulação do conteúdo, novos produtos buscam entrelaçar características as quais sejam referentes a ambos os gêneros, buscando com isso uma aproximação cada vez mais evidente. Se partirmos para a análise, por exemplo, da produção fotojornalística atual, poderemos observar uma necessidade de mais controle e mais aproximação com o tema nas produções. Novas narrativas e novos suportes, eis o desafio para os fotojornalistas conectados com a contemporaneidade. O interessante é que, diante desta necessidade de reportar com precisão, o fotojornalismo aproxima-se de forma latente com o fotodocumentarismo, buscando cada vez mais uma realidade além do primeiro clique. Vinculado a isso, o trabalho "coletivo" e uma preocupação estética também apontam essa produção para o campo das artes. A análise do trabalho do fotógrafo dinamarquês Peter Funch já nos oferece elementos para análise dessa encruzilhada conceitual. Um possível indicativo para o comportamento do campo fotográfico para os próximos anos? Ainda é cedo para afirmar...

\section{Referências}

BECKER, Howard. Art worlds. Berkeley, Los Angeles, Londres: University of California Press, 2008.

BUSCOMBE, Edward. Teoria contemporânea do cinema. V. 1 Fernão Pessoa Ramos (org.). São Paulo: Editora Senac, 2005.

CARVALHO, Victa. Cotidiano e experiência na fotografia contemporânea. Caxias do Sul: 
XXXIII Congresso Brasileiro de Ciências da Comunicação, 2010.

CONNOR, Steven. Teoria e valor cultural. São Paulo: Loyola, 1994.

COTTON, Charlote. A Fotografia como arte contemporânea. São Paulo: Editora WMF Martins Fontes, 2010.

COUCHOT, Edmond. A Tecnologia na Arte. Da fotografia à realidade virtual. Porto Alegre, Editora UFRGS, 2003.

CRARY, J. Techniques of observer. Cambridge: MIT Press, 1991

FABRIS, Annateresa. Identidades virtuais: uma leitura do retrato fotográfico. Belo Horizonte: Editora UFMG, 2004.

FONTCUBERTA, Joan. La Camara de Pandora: la fotografi@ después de la fotografia. Barcelona: Editora Gustavo Gili. 2010.

. El beso de Judas: Fotografia e Verdad. Barcelona: Editora Gustavo Gili. 1997.

GALARD, Jean. Beleza exorbitante: reflexões sobre o abuso estético. São Paulo: Editora Fap-Unifesp, 2012.

LEDO, Margarida. Documentalismo fotográfico: éxodos e identidad. Madrid: Ediciones Cátedra. 1998.

ROUILEE, André. A Fotografia entre o documento e arte contemporânea. São Paulo, SENAC, 2009.

\section{Links de imagens referentes ao site de Peter Funch:}

1. http://www.peterfunch.com/index.php?/ongoing/babel-tales/ (Série Babel Tales)

2. http://www.peterfunch.com/index.php?/ongoing/aftermath/ (Série Aftermatch 9/11) 